\title{
Author Index Vol. 38, 1995
}

Arievitch, I. 113 Astington, J.W. 179,214 Baltes, P.B. 349 Bruner, J. 203 Burgess, R.L. 159 Cole,M. 19 Engeström, Y. 19 Feldman, D.H. 315 Fischer, K.W. 302 Fleisher Feldman, C. 194 Gauvain, M. 25 Geert, P. van 322 Goldsmith, H.H. 142 Gottesman, I.I. 142 Gottlieb, G. 131, 165 Granott,N. 302

Halford, G.S. 65, 295 Harris, P. 235 IJzendoorn, M.H. van 170 Izard,C.E. 103 Kahn, P.H., Jr. 282 Kuhn,D. 1,293 Labouvie-Vief, G. 239 Leadbeater, B. 190 Lerner, R.M. 361 Lewis, M.D. 71 Lindenberger, U. 349 Lucariello, J. 2 McVicker Clinchy, B. 258 Manion, M. 239 Molenaar, P.C.M. 159 Moshman, D. 53,265

Olson, D.R. 179,214 Orwoll,L. 239 Pascual-Leone, J. 338 Raver, C. 190

Scarr, S. 154 Smedslund, J. 174 Sohmer, R. 332 Subbotsky, E. 217 Tomasello, M. 46

Turkheimer, E. 142 Veer, R. van der 113 Wertsch,J.V. 127,332 Youniss, J. 373 Zimmerman, B.J. 367 